\section{Reporting of potential immunogenicity with biologic drugs: clarity and accuracy required}

We welcome the study from Emery et $a l^{1}$ reporting the phase III trial comparing the biosimilar SB4 with originator etanercept. In this publication, the authors report comparable clinical efficacy and safety profile between both drugs, but an apparent difference in immunogenicity, with 'antidrug antibodies (ADAs)' reported in only $0.7 \%$ of patients taking SB4, compared with $13 \%$ with reference product, etanercept.

While the development of ADAs clearly has the potential to translate into the clinical situation, the science underpinning their detection (and also extrapolation to potential clinical effect) is complex, highly dependent on the assay system employed and often poorly reported. ${ }^{2}{ }^{3}$ We believe that the data on ADAs documented in this report to be confusing and, as presented, do not merit the headline conclusions drawn. In particular, we note only a minimal description of the assay system used to measure ADAs and sparse details of immunogenicity results (online supplementary appendix 9). We also note just one time point (week 4) with an apparent excess of ADAs in patients taking reference etanercept, with no or minimal detection of ADAs for either drug at any other time point.

To correctly interpret the results of this important part of the study, we believe that additional details are required: What was the full protocol for measurement of ADAs? At what cut-off point was 'positivity' considered? What were the titres of ADAs? What were the drug trough plasma concentrations and did the presence of apparent ADA correlate with these or with reports of adverse events? What potential mechanism would explain the one-off measurement of ADAs at 4 weeks alone, with one drug? Where did the ADAs go after 4 weeks as they could not be measured after that period? What was the rationale for reporting a 'week 24 overall ADA incidence,' when analyses of weekly ADA incidence apparently showed one transient excess 'positive' ADAs for one drug at 1 week and, is it appropriate to present this as clear evidence for immunogenicity?
We trust that further information able to address these important questions can soon be made available to allow the rheumatology and scientific community undertake a more suitable assessment of this important paper.

Robert J Moots, Alejandro Balsa, Gertjan Wolbink

University of Liverpool, Liverpool, UK

Correspondence to Professor Robert J Moots, University of Liverpool, Liverpool, UK; rjmoots@liv.ac.uk

Competing interests None declared.

Provenance and peer review Not commissioned; internally peer reviewed.

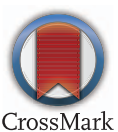

To cite Moots RJ, Balsa A, Wolbink G. Ann Rheum Dis 2016;75:e24.

Received 12 January 2016

Accepted 15 January 2016

Published Online First 4 February 2016

\section{Linked}

http://dx.doi.org/10.1136/annrheumdis-2016-209203

Ann Rheum Dis 2016;75:e24. doi:10.1136/annrheumdis-2016-209178

\section{REFERENCES}

1 Emery P, Vencovsk? J, Sylwestrzak A, et al. A phase III randomised, double-blind, parallel-group study comparing SB4 with etanercept reference product in patients with active rheumatoid arthritis despite methotrexate therapy. Ann Rheum Dis 2015; Published Online First 6 July 2015. http://dx.doi.org/10.1136/annrheumdis-2015207588

2 Felis-Giemza A, Moots RJ. Measurement of anti-drug antibodies to biologic drugs. Rheumatology (Oxford) 2015;54:1941-3.

3 van Schouwenburg PA, Rispens T, Wolbink GJ. Immunogenicity of anti-TNF biologic therapies for rheumatoid arthritis. Nat Rev Rheumatol 2013;9:164-72. 